\title{
Human Mesenchymal Stem Cells Promote Cancer Motility and Cytokine Secretion in vitro
}

\author{
A. Scherzed S. Hackenberg A. Radeloff K. Froelich K. Rak R. Hagen \\ N. Kleinsasser \\ Department of Otorhinolaryngology, Plastic, Aesthetic and Reconstructive Head and Neck Surgery, \\ University Hospital of Würzburg, Würzburg, Germany
}

\section{Key Words}

Cancer cell invasion - Cancer-stem cell interaction .

Cytokine secretion - Human mesenchymal stem cells .

Tumor pathophysiology

\begin{abstract}
Interactions of human mesenchymal stem cells (hMSC) with tumors are controversially discussed since there is evidence for both tumor progression as well as tumor inhibition by hMSC. The objective of the present study is to investigate whether hMSC support cell motility and cytokine secretion in a head and neck squamous cell carcinoma cell line ( $\mathrm{HLaC}$ 78). A spheroid model was generated in which the ultrastructure of spheroids was analyzed using scanning electron microscopy (SEM). The migration capability was monitored in a monolayer as well as in a spheroid model. The variation in migration and secretion of interleukin (IL)-6, IL-8 and vascular endothelial growth factor (VEGF), as well as the expression of the multidrug resistance gene (MDR-1) was investigated. Finally, the alteration in the cell cycle was analyzed by flow cytometry. SEM showed a tight cell-cell contact with extensive secretion of extracellular matrix. The migration and invasion capability of $\mathrm{HLaC} 78$ was enhanced by hMSC. Cancer cell motility was also increased by hMSC as well as
\end{abstract}

secretion of the cytokines IL-6, IL-8 and VEGF. hMSC did not induce the expression of MDR-1 in HLaC 78, and there was no alteration in the cell cycle of $\mathrm{HLaC} 78$ after cocultivation with hMSC. Our results confirm the important role of hMSC in cancer biology since both an enhancement of cell motility as well as cytokine secretion could be shown. However, based on these findings and those in the current literature, caution must be applied when using hMSC as a carrier for tumor therapy in cancer treatment.

(c) 2013 S. Karger AG, Base

\begin{tabular}{|c|c|}
\hline \multicolumn{2}{|c|}{ Abbreviations used in this paper } \\
\hline DMEM & Dulbecco's modified Eagle's medium \\
\hline ECM & extracellular matrix \\
\hline EM & expansion medium \\
\hline FCS & fetal calf serum \\
\hline HLaC 78 & head and neck squamous cell carcinoma cell line \\
\hline hMSC & human mesenchymal stem cells \\
\hline HNSCC & head and neck squamous cell cancer \\
\hline IL & interleukin \\
\hline MDR & multidrug resistance gene \\
\hline PBS & phosphate-buffered saline \\
\hline SEM & scanning electron microscopy \\
\hline
\end{tabular}

\section{KARGER}

E-Mail karger@karger.com

www.karger.com/cto
(C) 2013 S. Karger AG, Basel

$1422-6405 / 13 / 1985-0327 \$ 38.00 / 0$
Prof. Dr. Norbert Kleinsasser

Department of Otorhinolaryngology, Plastic, Aesthetic and Reconstructive Head and Neck Surgery, University Hospital of Würzburg

Josef-Schneider-Strasse 11, DE-97080 Würzburg (Germany)

E-Mail kleinsasser_n@ klinik.uni-wuerzburg.de 


\section{Introduction}

Surgery, chemotherapy, radiation and the combination of these modalities are all well-accepted treatment options for patients suffering from head and neck squamous cell cancer (HNSCC). Nevertheless, $40-60 \%$ of these patients develop locoregional recurrent disease or distant metastases [Prestwich et al., 2011]. Due to this high failure rate, as well as possible life-threatening side effects from current cancer therapies, there is a strong need for cell-specific cancer drug delivery systems. A variety of such delivery systems have been introduced in the current literature, e.g. functionalized nanomagnetic particles, cytokine-based anticancer therapy as well as cell-based drug delivery systems [Moritake et al., 2007; Hu et al., 2010]. In the case of cell-based delivery systems, the eligible candidate must have a tropism towards cancer. Human mesenchymal stem cells (hMSC) do in fact show a strong migration tendency towards cancer [Spaeth et al., 2012] and furthermore have the capacity to integrate directly into the tumor [Kidd et al., 2010]. Therefore, several studies have suggested hMSC as an appropriate candidate for drug delivery therapy. However, interactions between hMSC and cancer are ambiguous. Some studies show tumor progression and enhancement of tumor metastatic potential by hMSC. Such tumor progression is induced by cell-cell contact as well as by the secretion of several cytokines and growth factors [Karnoub et al., 2007; Lin et al. 2008; Rhodes et al., 2010]. In contrast, there are also reports of cancer inhibition and induction of apoptosis by hMSC [Khakoo et al., 2006; Zhu et al., 2009]. This overall lack of studies results in an incomplete understanding of the interactions between stem cells and cancer.

In a previous study, we were able to show an enhancement of cancer resistance against paclitaxel in the presence of hMSC, and a wide range of different cytokines were secreted by hMSC [Scherzed et al., 2011a]. Other studies have also shown that specific growth factors, such as vascular endothelial growth factor (VEGF), play an important role in tumor progression [Cao et al., 2010], and cytokines like interleukin (IL)-6 are responsible for cancer resistance against commonly used drugs, e.g. cisplatin [Hamada et al., 2005]. Cytokines are also involved in the process of cancer metastasis. Elevated IL-8 expression is associated with enhanced metastatic potential in various diseases, e.g. breast, gastric or ovarian cancer [Hamada et al., 2005; Yang et al., 2010]. A study performed by Chen et al. [1999] showed elevated IL-6, IL-8 and VEGF cytokine levels in patients with HNSCC compared to a disease-free control group.
Since hMSC could potentially be used as a carrier for cancer therapy, it is essential to analyze the effects of hMSC on carcinoma cell lines in vitro. The aim of the present study was to investigate their effect on a HNSCC cell line (HLaC 78), including morphological characteristics, using scanning electron microscopy (SEM), migration capability as well as secretion of VEGF, IL-6 and IL-8 in a coculture system of hMSC and HLaC 78. Furthermore, it was evaluated whether hMSC alter the cell cycle of HLaC 78 and the expression of the multidrug receptor (MDR)-1.

\section{Materials and Methods}

\section{hMSC Isolation and Culture}

hMSC were isolated from subcutaneous adipose tissue of 7 healthy donors undergoing liposuction for abdominoplasty or gynecomastia surgery. The study was approved by the Ethics Committee of the Medical Faculty of the University of Würzburg $(12 / 06)$ and informed consent was obtained from all individuals included. The isolation procedure was performed according to the methods described by Lee et al. [2004] and us [Scherzed et al., 2011 b]. Briefly, adipose tissue was extensively washed with phosphate-buffered saline (PBS) and enzymatically digested at $37^{\circ} \mathrm{C}$ for $3 \mathrm{~h}$ at a concentration of $15 \mathrm{mg}$ collagenase P (Roche Diagnostic, Mannheim, Germany) per $100 \mathrm{ml}$ lipoaspirate. To obtain the cell pellet, several washing and centrifugation steps were performed. The pellet was resuspended and passed through a $100-\mu \mathrm{m}$ cell strainer (BD Bioscience, Heidelberg, Germany) to remove debris. Cells were plated in culture flasks at $37^{\circ} \mathrm{C} / 5 \% \mathrm{CO}_{2}$. Expansion medium (EM) consisted of Dulbecco's modified Eagle's medium (DMEM; Gibco Invitrogen, Karlsruhe, Germany), 10\% fetal calf serum (FCS; Sigma-Aldrich, Schnelldorf, Germany) and 1\% penicillin/streptomycin. After $24 \mathrm{~h}$, hMSC were rinsed with PBS to remove residual nonadherent cells. Medium was exchanged every other day. When cells reached $>70 \%$ confluence, they were trypsinized with $0.25 \%$ trypsin (Gibco Invitrogen), resuspended in DMEM-EM and subcultured at a concentration of $2,000 \mathrm{cells} / \mathrm{cm}^{2}$. Cell morphology was analyzed by microscopy (Leica DMI 4000B Inverted Microscope; Leica Microsystems, Wetzlar, Germany).

All experiments were done in triplicate.

\section{Multidifferentiation Capacity}

Osteogenic differentiation was carried out in a 24 -well plate (BD Falcon, Heidelberg, Germany) with $1 \times 10^{4}$ cells/well until $70 \%$ confluence was reached. The osteogenic induction medium was prepared as described by Pittenger et al. [1999] and was composed of DMEM-EM, $10^{-7} \mathrm{M}$ dexamethasone, $10^{-3} \mathrm{M} \beta$-glycerophosphate and $2^{-4} \mathrm{M}$ ascorbate-2-phosphate (all Sigma-Aldrich). Every 3rd day, the medium was renewed. As a negative control, cells were maintained in DMEM-EM. The cells were stained according to the von Kossa method to show the presence of calcium mineral components. Adipogenic differentiation was performed in monolayer cultures as described by Pittenger et al. [1999]. hMSC were plated at a density of $1-2 \times 10^{4}$ cells/well. Adipogenic differentiation was induced by DMEM-EM, $10^{-7} \mathrm{M}$ dexa- 
methasone (Sigma-Aldrich) and $10^{-9} \mathrm{~g} / \mathrm{ml}$ recombinant human insulin. Staining with oil red $\mathrm{O}$ confirmed the presence of intracellular lipid droplets.

For chondrogenic differentiation, the pellet culture system was used. The cell pellets were cultured in a defined chondrogenic differentiation medium (Lonza, Basel, Switzerland) supplemented with $10^{-9} \mathrm{~g} / \mathrm{ml}$ transforming growth factor- $\beta_{3}$ (Sigma-Aldrich). The medium was replaced every $2-3$ days for 3 weeks. Thereafter, the pellets were embedded in Optimal Cutting Temperature Paraffin (Tissue-Tek ${ }^{\circledR}$ O.C.T ${ }^{\mathrm{TM}}$; Sakura Finetek, Zoeterwoude, The Netherlands). Cryosections were stained with Alcian blue to show the presence of glycosaminoglycans [Technau et al., 2011].

\section{Expression of Cell Surface Markers}

For cell surface profiling, hMSC were trypsinized, washed in PBS and incubated with 5\% FCS for $1 \mathrm{~h}$ on ice. After another washing step with PBS, cells were incubated with anti-CD105 (catalogue No. 555690), anti-CD73 (catalogue No. 550257), anti-CD90 (catalogue No. 559869), anti CD44 (catalogue No. 555478), anti CD45 (catalogue No. 555482), anti-CD34 (catalogue No. 550761) and anti-CD31 (catalogue No. 555446; all antibodies were obtained from BD Bioscience). Cell surface analyses were performed by flow cytometry (FACSCanto ${ }^{\mathrm{TM}}$; BD Bioscience).

\section{HNSCC Cell Line HLaC 78}

HLaC 78 was established from a lymph node metastasis of a laryngeal squamous cell carcinoma [Zenner et al., 1979]. HLaC 78 cells were grown in DMEM-EM and cultured at $37^{\circ} \mathrm{C}$ with $5 \% \mathrm{CO}_{2}$ in culture flasks. The medium was replaced every other day and passaging was performed after reaching $70-80 \%$ confluence by trypsinization with $0.25 \%$ trypsin (Gibco Invitrogen), washing with PBS (Roche Diagnostic) and seeding in new flasks or treatment wells. Experiments were performed using cells in the exponential growth phase.

\section{Generation of Multicellular Spheroids}

A 96-multiwell plate was coated with $0.1 \%$ agar (Sigma-Aldrich). After agar solidification, $0.2 \mathrm{ml}$ DMEM-EM containing either $6 \times 10^{3} \mathrm{HLaC} 78$ or $3 \times 10^{3} \mathrm{HLaC} 78$ and $3 \times 10^{3} \mathrm{hMSC}(\mathrm{HLaC}$ $78+$ hMSC $=$ coculture) were added to each well plate. After a period of $36 \mathrm{~h}, 3$-dimensional multicellular spheroids were visible.

\section{Scanning Electron Microscopy}

To evaluate morphological differences between spheroids made from hMSC, HLaC 78 and coculture, SEM was used. Spheroids were fixed overnight at $4^{\circ} \mathrm{C}$ with $2 \%$ glutaraldehyde in $0.1 \mathrm{M}$ phosphate buffer. Next, spheroids were treated with $2 \%$ osmium tetroxide in $0.1 \mathrm{M}$ phosphate-saccharose. After dehydration in graded ethanol series (35-100\%), specimens were dried using a critical point dryer. Spheroids were then coated with carbon, sputtered with gold palladium and viewed with an SEM (DSM 962; Zeiss, Oberkochen, Germany).

\section{Three-Dimensional Migration Assay}

In order to identify HLaC 78, cells were labeled with the fluorochrome 1,1'-dioctadecyl-3,3,3',3'-tetramethylindocarbocyanine perchlorate (Gibco Invitrogen). Next, spheroids consisting of $6 \times$ $10^{3} \mathrm{HLaC} 78$ and spheroids made of $3 \times 10^{3} \mathrm{HLaC} 78$ and $3 \times 10^{3}$ hMSC (coculture) were generated as mentioned above. After $72 \mathrm{~h}$, spheroids were transferred to well plates without coating in an ad- herent condition. Here, the cells were able to spread in the well plate out of the spheroids. To determine the migration area, cells were imaged directly after being transferred and after $24 \mathrm{~h}$ using an inverted microscope (Leica, DMI 4000B). The migration area was calculated using ImageJ software (version $1.43 \mathrm{u}$ ), a freeware program (http://rsbweb.nih.gov/ij; $\mathrm{n}=7$ ).

\section{Scratch Assay}

Two groups were analyzed, $1 \times 10^{5} \mathrm{HLaC} 78$ alone and $0.5 \times$ $10^{5} \mathrm{HLaC} 78$ in coculture with $0.5 \times 10^{5}$ hMSC, respectively, and incubated with DMEM-EM in 12-well plates for $24 \mathrm{~h}$ at $37^{\circ} \mathrm{C}$. Then, a linear wound was generated with a sterile $1-\mathrm{ml}$ plastic tip. Any cellular debris was removed by washing with PBS. To analyze the relative migration, plates were photographed (Leica, DMI $4000 \mathrm{~B}$ ) and the percentage of the wound closure was evaluated. The distance from each wound border at time $\mathrm{t}=0 \mathrm{~h}$ was defined as $0 \%$ wound closure. After $24 \mathrm{~h}$, the percent wound closure was measured $(n=7)$.

\section{Quantitative Analysis of VEGF, IL-6 and IL-8 Secretion}

Spheroids were generated as described above and transferred in a well plate without coating. To evaluate the secretion of VEGF, IL- 6 and IL-8, the supernatants were collected and stored in sterile tubes at $-20^{\circ} \mathrm{C}$ until use. DMEM-EM served as a control. VEGF, IL-6 and IL- 8 concentrations were determined using the following ELISA kits: human VEGF ELISA kit (Abnova, Taipei, Taiwan, ROC), and human IL-6 and IL-8 ELISA kits (Hölzel Diagnostika, Köln, Germany). The experiments were carried out in duplicate. The ELISA plate was read at $450 \mathrm{~nm}$ (Titertek Multiskan PLUS; Labsystems, Helsinki, Finland). VEGF, IL-6 and IL-8 concentrations $(\mathrm{pg} / \mathrm{ml})$ were determined by constructing a standard curve using recombinant VEGF, IL-6 and IL-8. Statistical evaluation included the comparison of monocultures (hMSC or HLaC 78) versus coculture (hMSC and HLaC 78) regarding secretion of cytokines (IL-6, IL-8 and VEGF).

\section{Total RNA Extraction, cDNA Synthesis and Real-Time PCR}

The effects of hMSC on MDR-1 gene expression in HLaC 78 were investigated after cocultivation in a Transwell system (Nunc, Langenselbold, Germany). $1 \times 10^{5} \mathrm{HLaC} 78$ were cultivated on the bottom and $1 \times 10^{5}$ hMSC were seeded on the Transwell. The Transwell coculture was chosen in order to culture each cell system separately. This system allows both cell types to contact each other by their cytokines only, which were secreted in a paracrine manner. After $48 \mathrm{~h}$, the TRIzol method was used as described by the manufacturer in order to extract total RNA from HLaC 78 after coculture with hMSC. The extracted total RNA was reverse transcribed to cDNA. For the quantification of gene expression, the SYBR Green PCR master mix kit (Applied Biosystems, Foster City, Calif., USA) was used. The MDR-1 primer was purchased from Applied Biosystems (forward primer $5^{\prime}$-AGAAAGCGAAGCAGTGGTTCA-3' and reverse primer $5^{\prime}$-CGAACTGTAGACAAACGATG-AGCTA- $\left.3^{\prime}\right)$. The amplifications for gene quantification were: $50^{\circ} \mathrm{C}$ for $2 \mathrm{~min} ; 95^{\circ} \mathrm{C}$ for $10 \mathrm{~min}$, and 40 cycles at $95^{\circ} \mathrm{C}$ for $15 \mathrm{~s}$ and $60^{\circ} \mathrm{C}$ for $1 \mathrm{~min}$. As an endogenous control, the GAPDH gene was used. The HNSCC cell line HLaC 79 had been established from a lymph node metastasis of a laryngeal squamous cell carcinoma [Zenner et al., 1979]. A multiresistant clone of HLaC 79 [Schmidt et al., 2009] with high expression of MDR-1 was used as a positive control. 

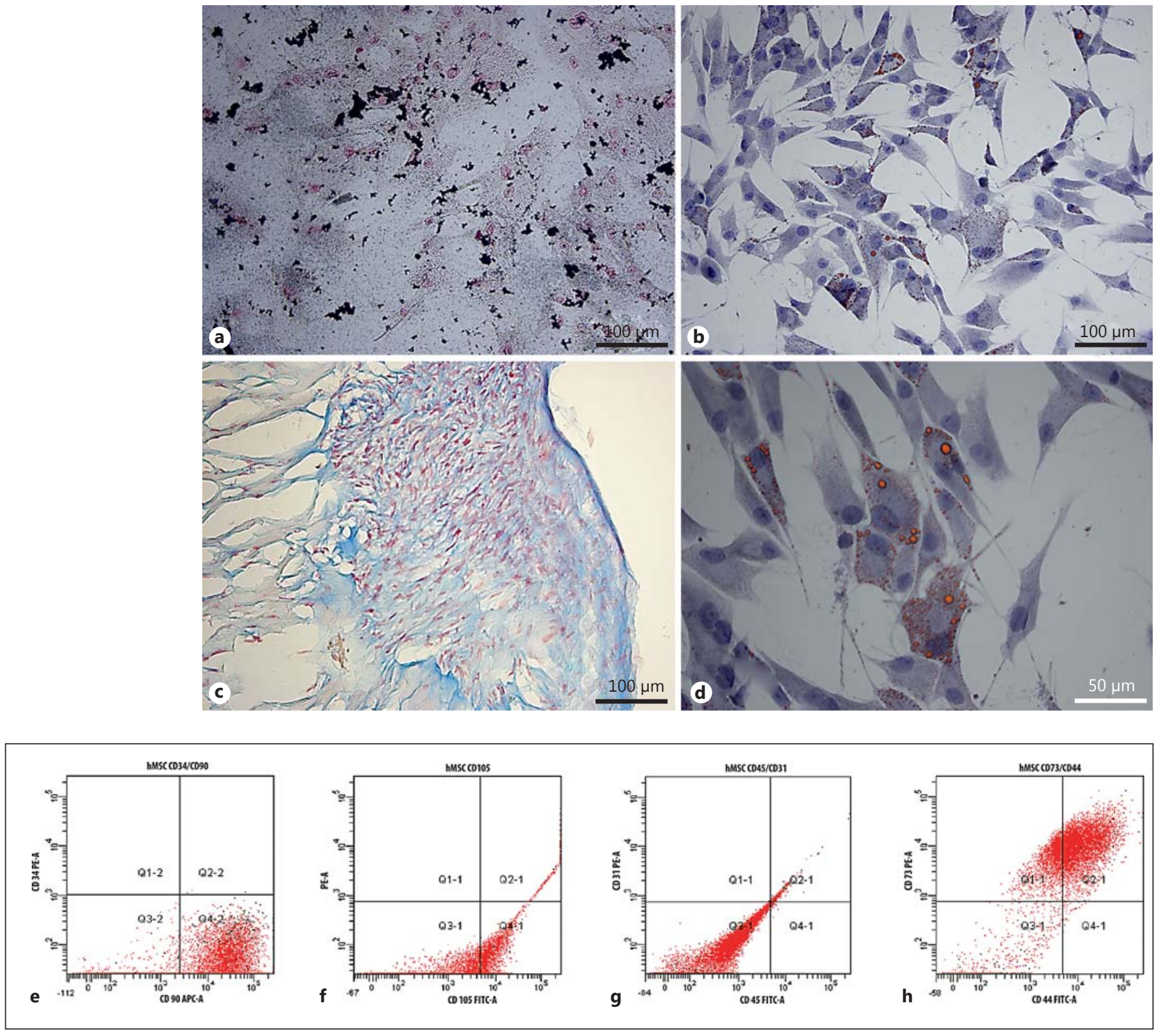

Fig. 1. The differentiation of hMSC into osteocytes, adipocytes and chondrocytes was confirmed by von Kossa, Alcian blue and oil red O staining. a Microscopic analysis of hMSC cultured in osteogenic medium. The von Kossa staining characterizes the mineralization by staining the calcium mineral component dark brown. b Microscopic analysis of hMSC cultured in adipogenic medium. Adipogenic differentiation was confirmed by staining with oil red $\mathrm{O}$ to show the presence of intracellular lipid droplets (at higher

\section{Cell Cycle Analysis}

To analyze the effect of hMSC on the cell cycle of HLaC 78, a Transwell system (Nunc) was used. $1 \times 10^{5} \mathrm{HLaC} 78$ were cultivated on the bottom and $1 \times 10^{5} \mathrm{hMSC}$ were seeded on the Transwell. Following a 48-hour period, the cell cycle was analyzed as magnification in d). c Microscopic analysis of hMSC incubated in chondrogenic medium. The cryosections were stained with Alcian blue to show the presence of glycosaminoglycans. Flow-cytometric analysis of surface markers routinely used for characterization of hMSC showed that they were highly positive for CD105, CD90, CD73 and CD44, but negative or weakly positive for CD45, CD34 and CD31. e CD34/CD90. f CD105. g CD31/CD45. h CD73/ CD44.

follows. First, HLaC 78 were trypsinized and washed twice with cold PBS. Then, cells were fixed in $1 \mathrm{ml} 70 \%$ cold ethanol in test tubes and incubated for $2 \mathrm{~h}$ at $4^{\circ} \mathrm{C}$ in the dark. After incubation, cells were centrifuged at $500 \mathrm{~g}$ for $5 \mathrm{~min}$ at $4^{\circ} \mathrm{C}$ and resuspended in $500 \mu \mathrm{l}$ propidium iodide (BD Bioscience). After another incuba- 

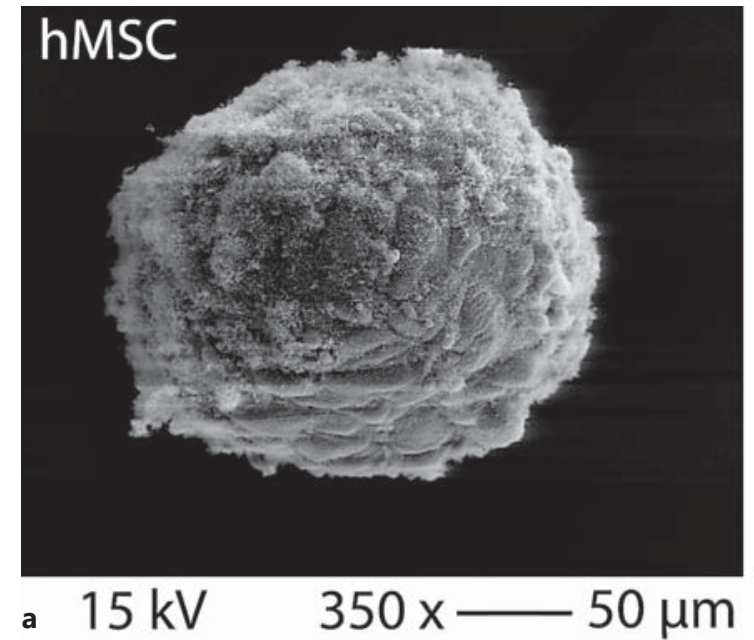

$350 x$
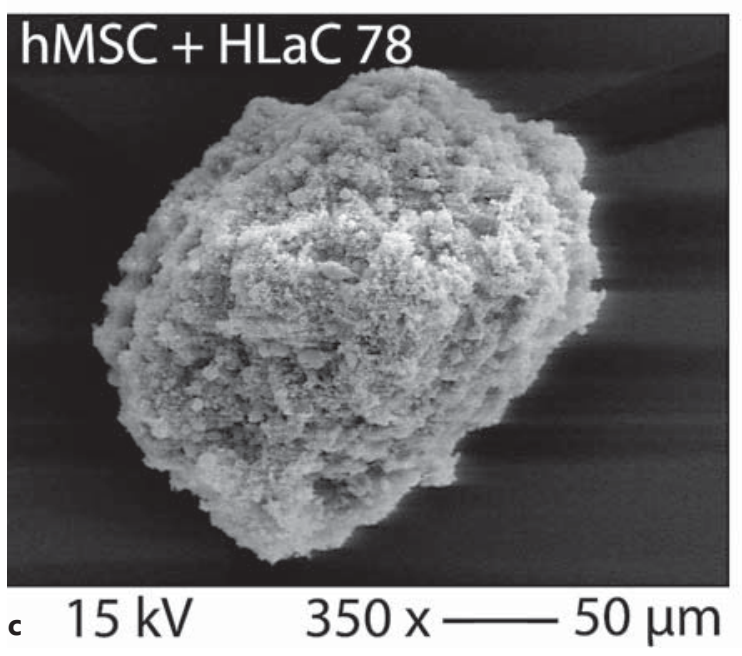
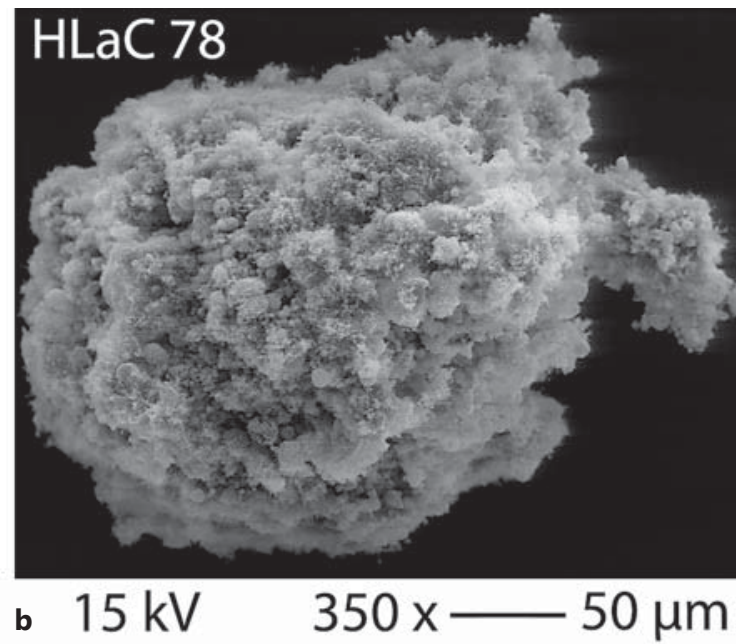

Fig. 2. Evaluation of the spheroid ultrastructure by SEM. Under the SEM, all spheroid hMSC (a), HLaC 78 (b) and hMSC in coculture with HLaC 78 (c) showed a tight cell-cell contact. HLaC 78 and coculture showed an extensive secretion of ECM compared to hMSC alone.

tion at $4^{\circ} \mathrm{C}$ in the dark for $15 \mathrm{~min}$, cells were analyzed with flow cytometry within $1 \mathrm{~h}$. HLaC 78 cultivated in RPMI-EM served as a control $(n=7)$.

\section{Statistics}

All data were transferred to standard spreadsheets and analyzed by the statistical software GraphPad Prism (version 4.0). The Kruskal-Wallis test was carried out for all tests to evaluate statistical significance. Differences were considered significant when $\mathrm{p}<$ 0.05 .

\section{Results}

\section{Multidifferentiation Potential of hMSC}

hMSC were able to differentiate into osteocytes, chondrocytes and adipocytes, which was confirmed by von Kossa, Alcian blue and oil red O staining. Cells were tested with flow cytometry for the presence of typical hMSC surface markers. hMSC were positive for CD105, CD90, $\mathrm{CD} 7$ and $\mathrm{CD} 44$, and negative or weakly positive for CD45, CD34 and CD31 (fig. 1).

\section{Morphology of Spheroids and Three-Dimensional} Migration Assay

Spheroids in coculture appeared slightly bigger than spheroids made of HLaC 78 alone. However, this was not statistically significant. Spheroids were well shaped and adjusted in the three-dimensional structure. Although they were transferred using a pipette, spheroids kept their structure. The ultrastructure of spheroids was measured using SEM. Under the SEM, all spheroids (HLaC 78, hMSC and coculture) showed a tight cell-cell contact. Spheroids made of HLaC 78 and coculture had extensive secretion of extracellular matrix (ECM). Due to the high secretion of ECM, cells were not visible on the surface (fig. 2). 

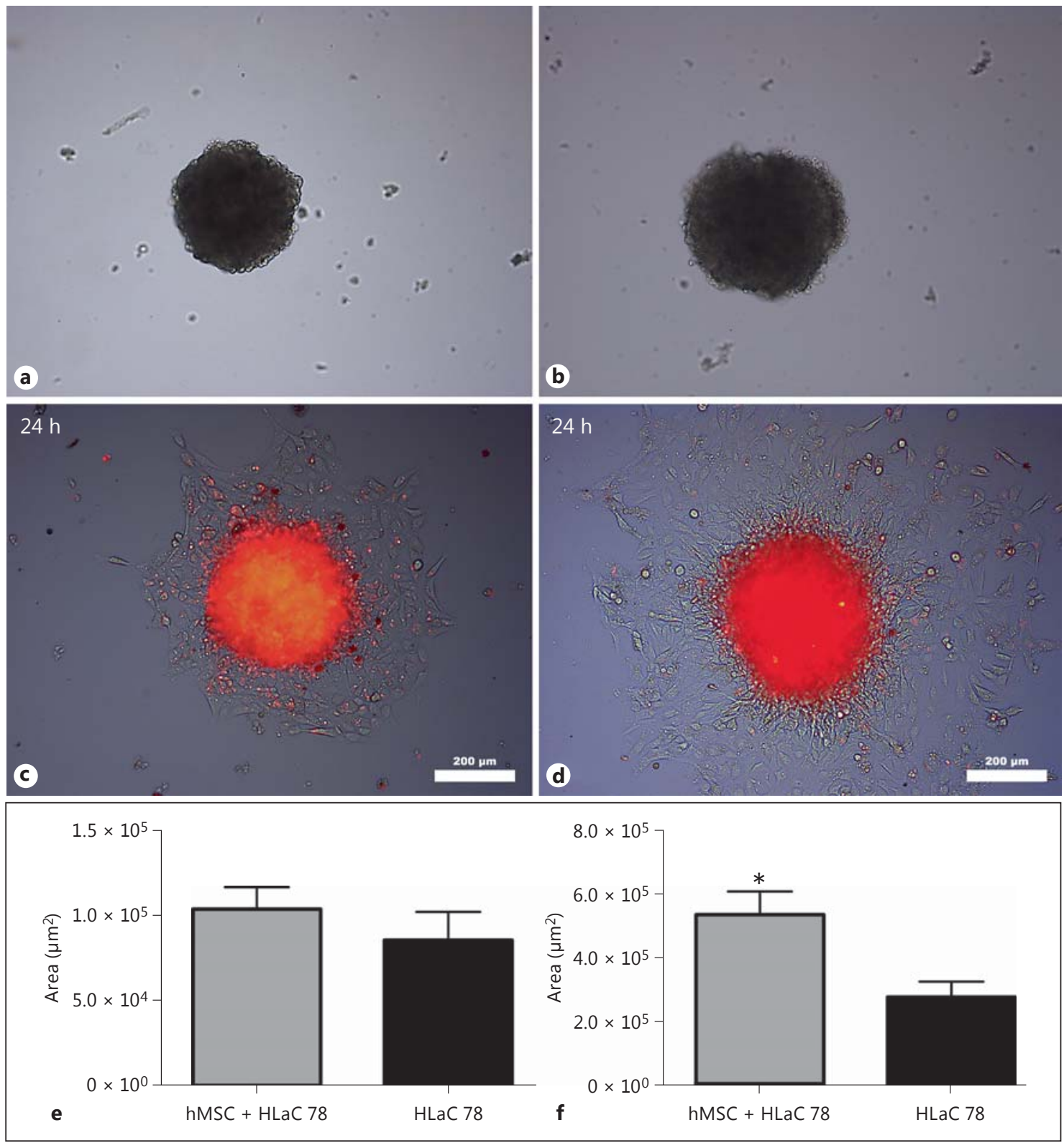

Fig. 3. Spheroids made of HLaC 78 (a) and hMSC in coculture with HLaC 78 (b) were transferred to well plates without coating in an adherent condition. In this condition, cells gain the ability to spread out into the well plate. HLaC 78 (c) and hMSC in coculture with HLaC 78 (d) were labeled with the fluorochrome 1,1'-dioctadecyl-3,3,3', $3^{\prime}$-tetramethylindocarbocyanine. The mi-

In the adherent condition, cells were able to spread out in the well plate. This migration area was significantly larger in spheroids made of hMSC and HLaC 78 than spheroids made of HLaC 78 alone (fig. 3). gration area was measured using ImageJ software. There was no significant difference between spheroids composed of HLaC 78 and coculture (e). The migration area of $\mathrm{HLaC} 78$ in coculture with hMSC was significantly larger than that of HLaC 78 alone (f). * Significant difference of cell migration between $\mathrm{HLaC} 78$ alone and HLaC 78 in coculture with hMSC.

\section{Cell Motility Assay}

The scratch test was used as a diagnostic instrument to evaluate the motility of $\mathrm{HLaC} 78$ in the presence of hMSC. After a repair period of $24 \mathrm{~h}$ at $37^{\circ} \mathrm{C}$ and $5 \% \mathrm{CO}_{2}$, the percentage of wound closure in coculture was enhanced compared to HLaC 78 alone (fig. 4). 

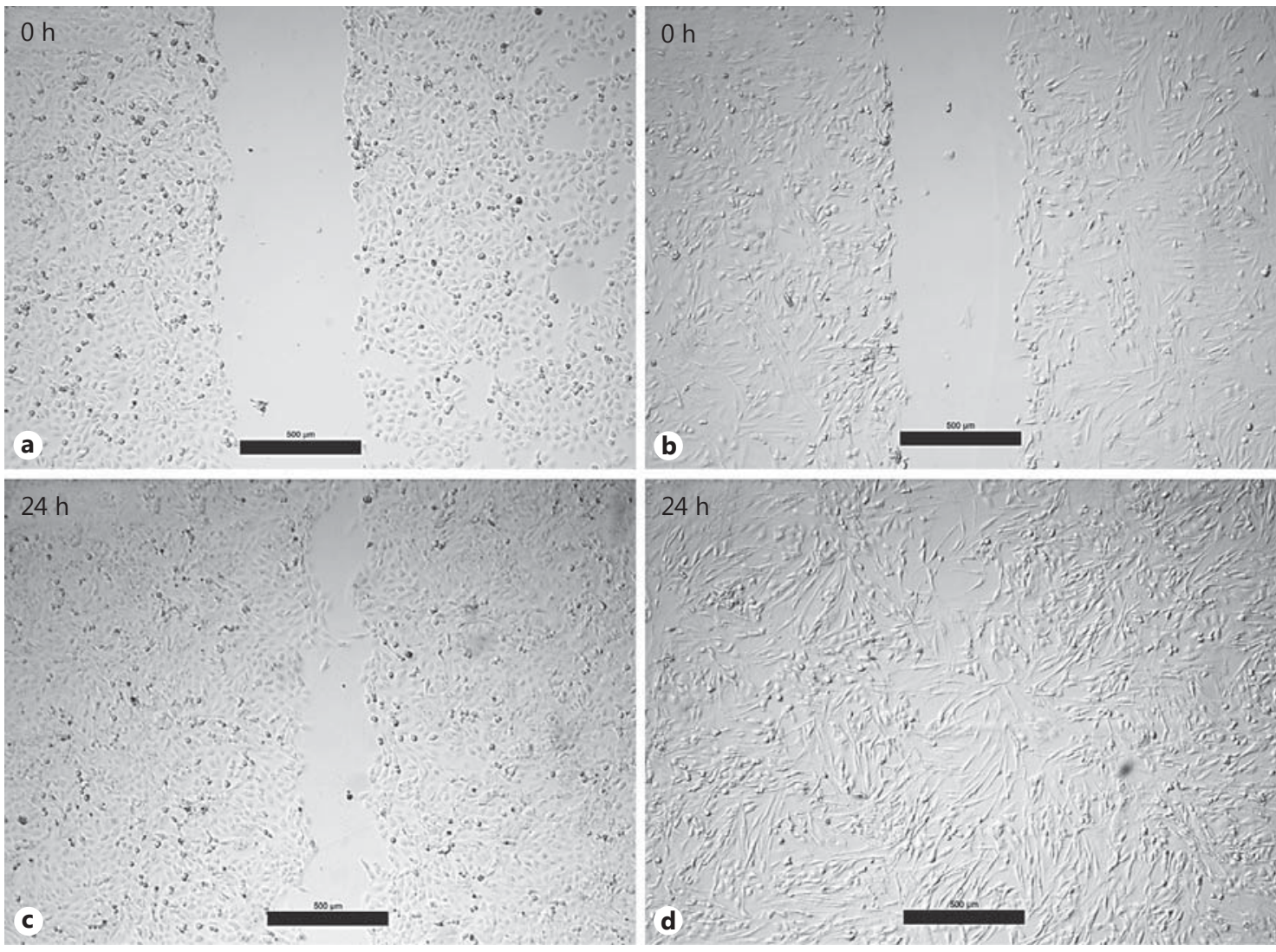

Fig. 4. The scratch test was used to evaluate cell motility of HLaC 78 (a) and HLaC 78 in coculture with hMSC (b). After $24 \mathrm{~h}$, the well plates were photographed in order to evaluate the migration of the cells into the wound area for HLaC 78 (c) and hMSC in coculture with $\mathrm{HLaC} 78$ (d). The percentage of wound closure in coculture was significantly enhanced $(\mathrm{p}<$ $0.05)$ compared to HLaC 78 alone (e). * Significant difference of cell motility between $\mathrm{HLaC} 78$ alone and HLaC 78 in coculture with hMSC. hMSC and HLaC 78 in coculture achieved almost $80 \%$ wound closure, whereas HLaC 78 alone only reached approximately $50 \%$ wound closure.

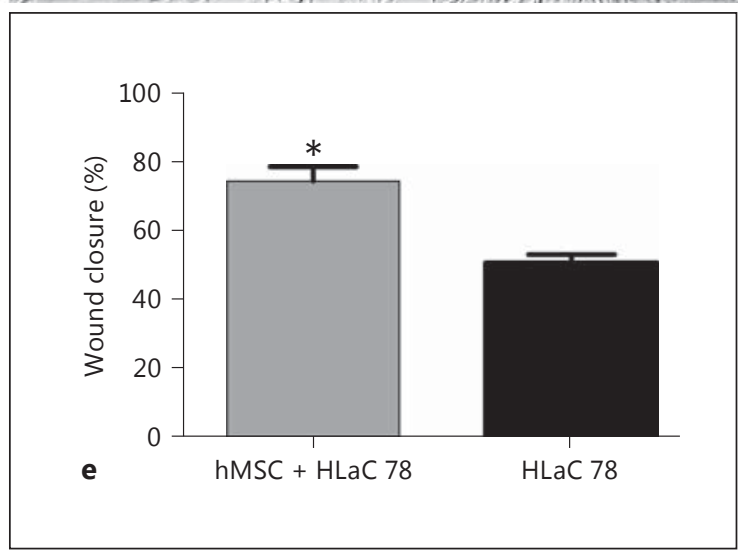

Quantitative Analysis of VEGF, IL-6 and IL-8

Supernatants of hMSC, coculture and HLaC 78 were used to determine the secretion of VEGF, IL- 6 and IL- 8 quantitatively. hMSC as well as $\mathrm{HLaC} 78$ showed secretion of VEGF, which was enhanced in coculture. The secretion of IL-6 was very low in HLaC 78. hMSC alone and in coculture showed high secretion of IL-6. There was no difference in IL-6 secretion between hMSC and coculture. hMSC showed more IL-8 secretion than HLaC 78. There was an enhancement of IL-8 secretion in coculture (fig. 5).

\section{MDR-1 Gene Expression and Alteration of the Cell Cycle}

After cocultivation of hMSC and HLaC 78, the expression of MDR-1 was evaluated using real-time PCR. There was no difference in MDR-1 gene expression before and after cocultivation. HLaC 78 was MDR-1 negative (fig. 6). The cocultivation did not affect the cell cycle as shown in the flow-cytometric analysis (fig. 7). 


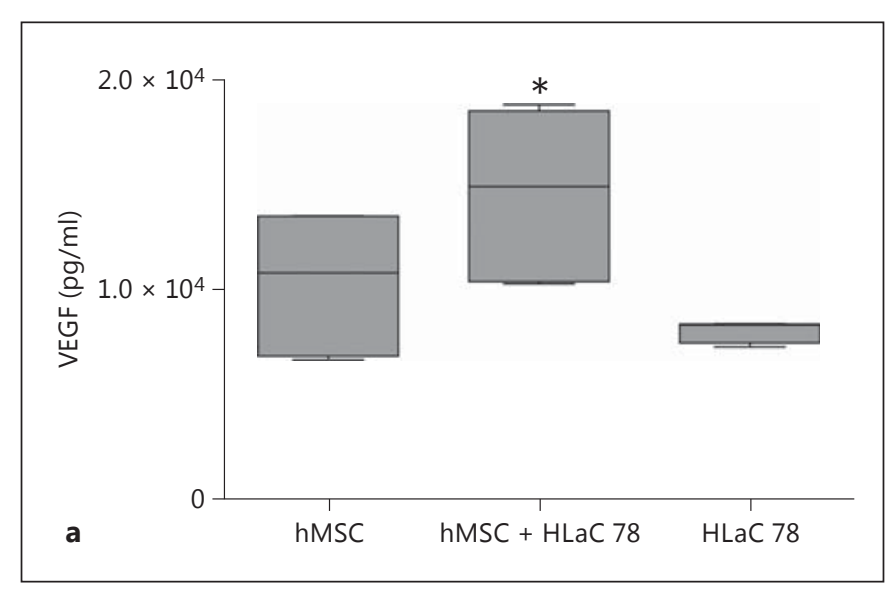

Fig. 5. Supernatants of hMSC, hMSC in coculture with HLaC 78 and $\mathrm{HLaC} 78$ alone were used to quantitatively determine the secretion of VEGF, IL-6 and IL-8. VEGF secretion was enhanced significantly in coculture (a). The secretion of IL-6 was low in HLaC 78. hMSC alone and in coculture showed high secretion of IL-6. There was no significant difference in IL-6 secretion between hMSC and hMSC in coculture with HLaC 78 (b). The secretion of IL-8 was significantly lower in HLaC 78 compared to hMSC. This was enhanced significantly in coculture $(\mathbf{c}){ }^{*}$ Significant difference of cytokine secretion between HLaC 78 alone and HLaC 78 in coculture with hMSC.

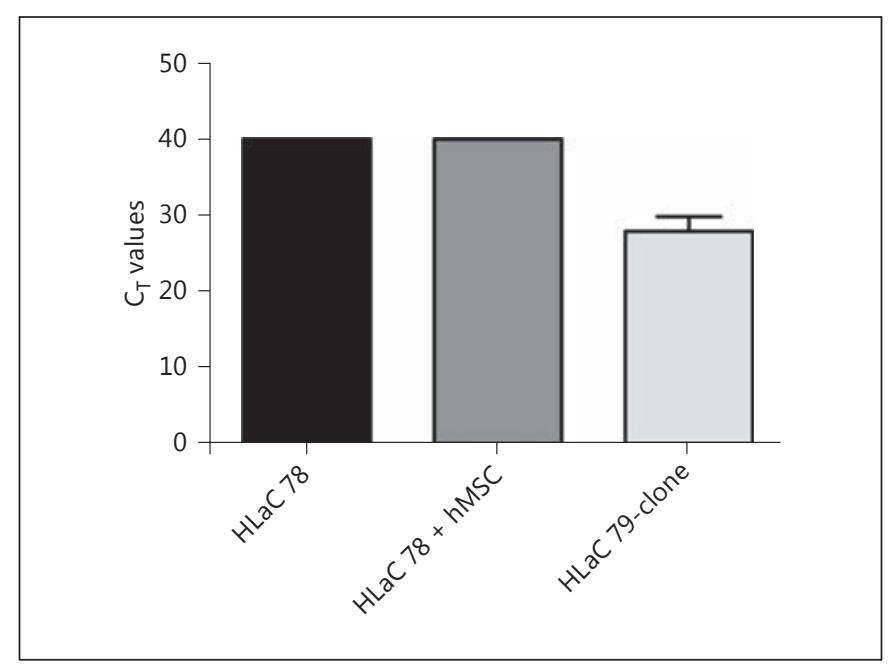

Fig. 6. After cocultivation of hMSC and HLaC 78 in a Transwell system, the expression of MDR-1 was evaluated using real-time PCR. Cycle threshold $\left(\mathrm{C}_{\mathrm{T}}\right)$ values of MDR-1 are shown. Clone-1, an established paclitaxel-resistant cell line with high MDR-1 expression, was used as a positive control. HLaC 78 did not express MDR-1 after cocultivation with hMSC. Clone-1 showed MDR-1 expression.
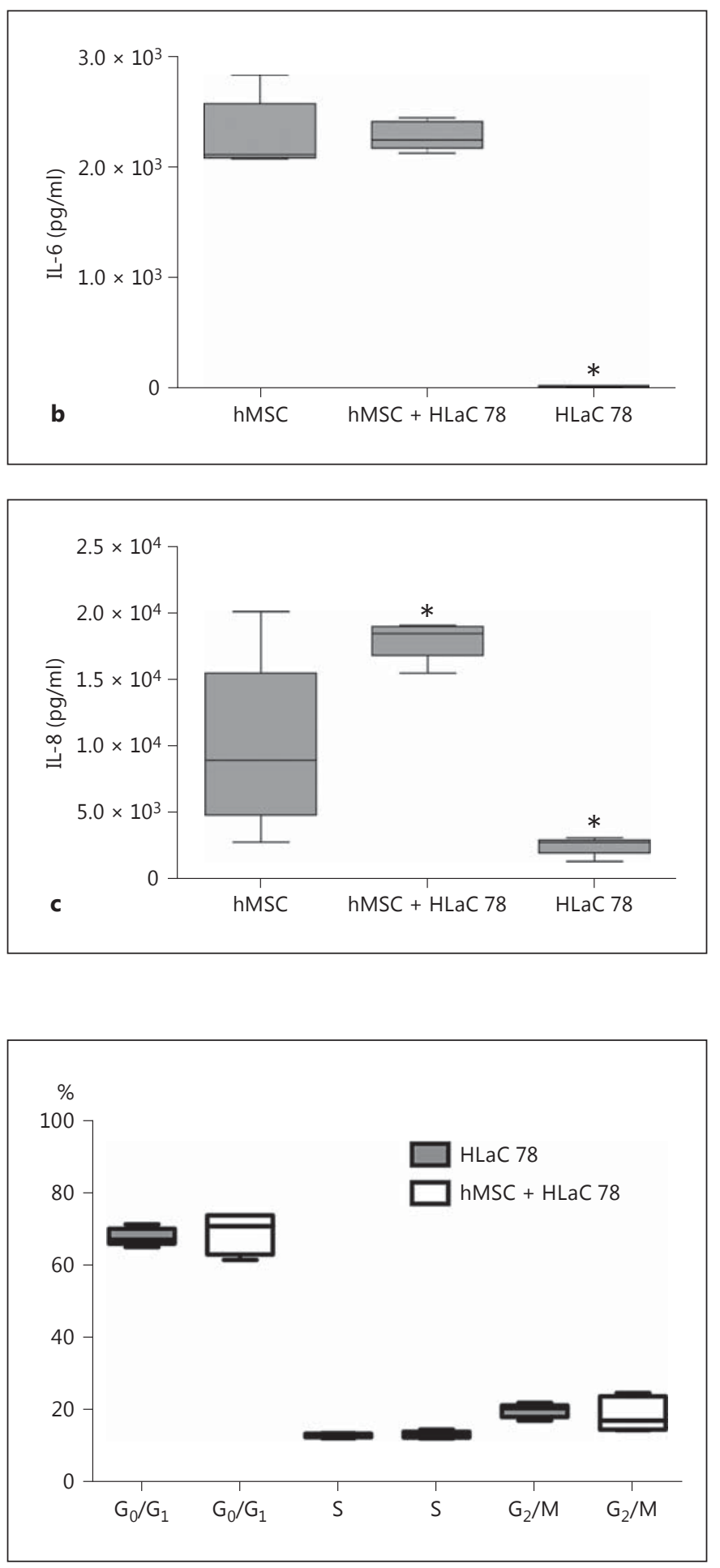

Fig. 7. To analyze the effect of hMSC on the cell cycle of HLaC 78, a Transwell system was used. After $48 \mathrm{~h}$, the cell cycle was analyzed with a flow cytometer. There was no difference in the $G_{0} / G_{1}, S$ and $\mathrm{G}_{2} / \mathrm{M}$ cycle. The cocultivation also did not affect the cell cycle. 


\section{Discussion}

\section{Drug Delivery Systems}

Several drug delivery systems for tumor therapy have been introduced and discussed in the current literature. Functionalized magnetic nanoparticles as carriers of pharmaceuticals and biomolecules [Moritake et al., 2007], stealth liposomes as a targeted delivery mechanism for doxorubicin [Li et al., 2009] as well as small interfering RNA [Fujita et al., 2013] are all well-investigated tools which show promising results. However, one major disadvantage of nanoparticles is agglomeration, which may lead to occlusion of the vascular system. Furthermore, nanoparticles would be separated by the reticuloendothelial system [Li et al., 2011]. The liposomes are rapidly recognized as well and cleared by the reticuloendothelial system from the circulating blood [Hu et al., 2012]. Therefore, a potential solution may be to use mesenchymal stem cells. On the other hand, the tumor vasculature seems to play an important role in therapy failure. Cancer has an abnormal vascular system with heterogeneous perfusion. The poorly perfused regions confer resistance to various treatments, even to immunotherapies [Jain, 2013].

hMSC, with their ability to be recruited by damaged tissues, inflammation and cancer, seem to be a very promising vehicle for cancer treatment. Consequently, hMSC have been used as a vehicle for viral vectors for gene delivery [Kucerova et al., 2007; Cavarretta et al., 2010]. However, cancer therapy with viral vectors such as retroviral vector-mediated gene transfer unfortunately involves numerous risks. For example, the retrovirus could integrate into the host cell chromosomes causing insertional mutagenesis and oncogene activation [Anson, 2004; Sadelain, 2004]. As a result of oncogenic activation, hMSC have been investigated as a delivery system, which is anchored to anticancer drugs. Nevertheless, the effects of hMSC on cancer are discussed controversially in the literature.

\section{Pro and Contra of Stem Cells}

The lack of studies in this area results in an incomplete understanding of the interactions between stem cells and cancer. In an experimental setting, Karnoub et al. [2007] could show that hMSC enhanced the metastatic potential of breast carcinoma cells. This effect was due to the de novo secretion of RANTES, which represents a potent cytokine responsible for cancer cell motility, invasion and migration. The secretion of RANTES by hMSC was also shown in our previous study [Scherzed et al., 2011a]. In our current work, we could clearly show an enhancement in cancer cell motility during cocultivation with hMSC. HLaC 78 gained enhanced motility in the scratch assay as well as in the three-dimensional migration assay. Rhodes et al. [2010] found an enhancement in tumor growth after co-injection of hMSC and breast carcinoma cell line cells. They were able to show a hormone-independent growth of cancer cells when co-injected with hMSC.

hMSC have the ability to integrate into tumor stroma and differentiate into cancer-associated fibroblasts [Direkze et al., 2006; Lorusso and Rüegg, 2008; Spaeth et al., 2009]. It is well known that cancer-associated fibroblasts mark the beginning of cancer invasion [De Wever and Mareel, 2003]. Furthermore, hMSC take part in cancer neoangiogenesis by producing angiogenic factors as well as by differentiation into pericytes and endothelial cells [Bergfeld and DeClerck, 2010; Bexell et al., 2010]. However, in contrast to studies showing the tumor-supporting potential of hMSC, there are also studies indicating anticancer effects. Khakoo et al. [2006] showed an inhibition of Karposi sarcoma cells after in vivo application of hMSC. They could demonstrate that hMSC suppressed the activity of Akt protein kinase. The reason for these contradictory findings may be explained by the use of different stem cell sources as well as different donor ages. For example, apoptosis of promyelocytic leukemia cells is inhibited by adipogenic-differentiated hMSC from bone marrow [Tabe et al., 2004], whereas hMSC isolated from umbilical blood stimulate cancer cell apoptosis [Sun et al., 2009]. This shows that different stem cell sources cause a variety of effects on cancer cells. Concerning sorted cells with specific markers (positive for CD73/CD90/CD105 and negative for CD31, CD34 and CD45), there may be an advantage in 'pure' stem cell populations. The latter may avoid contamination with other cells from the hematopoietic system. It will be a challenging mission to investigate the effects of sorted versus unsorted stem cells in a cancer microenvironment.

\section{Resistance Mechanism and Cytokine Secretion}

Solid tumors have a complex microenvironment, which includes several types of normal cells, malignant cells as well as ECM. Due to this microenvironment and the leaky vasculature, the distribution of cytotoxic medications is limited [Grantab and Tannock, 2012]. This resistance mechanism could be overcome with agents that modify the cell-cell or cell-matrix adhesion [Grantab and Tannock, 2012]. Further resistance mechanisms are disturbed convective transport within the chaotic vascular compartment, spatiotemporally uneven distribution 
within the tissue, significant shunt flow and the extravascular space [Multhoff and Vaupel, 2012]. The high interstitial fluid pressure is one of the main reasons for the failure of targeted therapy with macromolecules as well as nanoparticles.

IL-6, IL-8 and VEGF are elevated in patients with HNSCC compared to the control group [Chen et al., 1999]. IL-6, a multifunctional regulator of immune responses and hematopoiesis, influences the proliferation and invasion potential of head and neck cancer directly [Kanazawa et al., 2007]. A study conducted by Cohen et al. [2012] showed platinum resistance of ovarian cancer cells mediated by IL-6. This resistance towards cisplatin was reversible by blocking IL-6.

The secretion of IL- 8 promotes profound effects in the tumor microenvironment and biology. It leads to an enhancement of cell proliferation, survival and chemoresistance by an autocrine signaling pathway [Waugh and Wilson, 2008]. According to Waugh and Wilson [2008], IL-8 promotes cell invasion, migration as well as the induction of tumor-associated macrophages. These macrophages secrete growth factors that influence cancer growth as well. The coculture of hMSC and HLaC 78 had marked effects on both IL- 6 and IL- 8 secretion. In particular, the secretion of IL- 8 was significantly enhanced after cocultivation of HLaC 78 and hMSC. The cocultivation also influenced the secretion of VEGF. Overexpression of VEGF results in tumor angiogenesis, which leads to tumor progression and a poor prognosis in several cancer systems [Hicklin and Ellis, 2005]. VEGF secretion was elevated in coculture, which indicates a mutual interference.

In a previous study, we showed enhanced resistance of HLaC 78 towards paclitaxel, which was induced by hMSC. Paclitaxel is eliminated by MDR-1. Thus, the analysis of MDR-1 expression in HLaC 78 after cocultivation seemed logical. PCR revealed that there was no induction of MDR-1 gene expression in $\mathrm{HLaC} 78$, and $\mathrm{HLaC} 78$ were MDR-1 negative after cocultivation.

We further evaluated alterations in the cell cycle, which might have had an influence on the resistant behavior of HLaC 78, but the cell cycle did not show any alteration. Therefore, we assume that the paclitaxel resistance could be induced by secretion of cytokines such as IL- 6 and IL8. Regarding possible shortcomings of the applied method, the crucial direct cell-cell contact was not investigated here. However, the paracrine cytokine secretion warranted analysis as well and the Transwell model investigating supernatants proved appropriate to investigate these paracrine cytokine secretion effects. In future studies, the effects of direct cell-cell contacts will be analyzed according to the method used by Dumont et al. [2013].

According to our findings and the current literature, hMSC seem to play an important role in cancer angiogenesis, motility and the inhibition of apoptosis. Further investigations on the interaction of hMSC and cancer cells in terms of resistance mechanisms, gene expression and the comparison of in vitro and in vivo results are recommended.

\section{References}

Anson, D.S. (2004) The use of retroviral vectors for gene therapy - what are the risks? A review of retroviral pathogenesis and its relevance to retroviral vector-mediated gene delivery. Genet Vaccines Ther 2: 1-9.

Bergfeld, S.A., Y.A. DeClerck (2010) Bone marrow-derived mesenchymal stem cells and the tumor microenvironment. Cancer Metastasis Rev 29: 249-261.

Bexell, D., S. Scheding, J. Bengzon (2010) Toward brain tumor gene therapy using multipotent mesenchymal stromal cell vectors. Mol Ther 8: 1067-1075.

Cao, R., Y. Xue, E.M. Hedlund, Z. Zhong, K. Tritsaris, B. Tondelli, F. Lucchini, Z. Zhu, S. Dissing, Y. Cao (2010) VEGFR1-mediated pericyte ablation links VEGF and PlGF to cancerassociated retinopathy. Proc Natl Acad Sci USA 107: 856-861.
Cavarretta, I.T., V. Altanerova, M. Matuskova, L. Kucerova, Z. Culig, C. Altaner (2010) Adipose tissue-derived mesenchymal stem cells expressing prodrug-converting enzyme inhibit human prostate tumor growth. Mol Ther 18: 223-231.

Chen, Z., P.S. Malhotra, G.R. Thomas, F.G. Ondrey, F.C. Duffey, C.W. Smith, I. Enamorado, N.T. Yeh, G.S. Kroog, S. Rudy, L. McCullagh, S. Mousa, M. Quezado, L.L. Herscher, C. Van Waes (1999) Expression of proinflammatory and proangiogenic cytokines in patients with head and neck cancer. Clin Cancer Res 5: 1369-1379.

Cohen, S., I. Bruchim, D. Graiver, Z. Evron, V. Oron-Karni, M. Pasmanik-Chor, R. Eitan, J. Bernheim, H. Levavi, A. Fishman, E. Flescher (2012) Platinum-resistance in ovarian cancer cells is mediated by IL- 6 secretion via the increased expression of its target cIAP-2. J Mol Med 12: 1432-1440.

\footnotetext{
De Wever, O., M. Mareel (2003) Role of tissue stroma in cancer cell invasion. J Pathol 200: 429-447.

Direkze, N.C., R. Jeffery, K. Hodivala-Dilke, T. Hunt, R.J. Playford, G. Elia, R. Poulsom, N.A. Wright, M.R. Alison (2006) Bone marrowderived stromal cells express lineage-related messenger RNA species. Cancer Res 66: 1265-1269.

Dumont, N., B. Liu, R.A. Defilippis, H. Chang, J.T. Rabban, A.N. Karnezis, J.A. Tjoe, J. Marx, B. Parvin, T.D. Tlsty (2013) Breast fibroblasts modulate early dissemination, tumorigenesis, and metastasis through alteration of extracellular matrix characteristics. Neoplasia 15: 249-262.
} 
Fujita, T., K. Yanagihara, F. Takeshita, K. Aoyagi, T. Nishimura, M. Takigahira, F. Chiwaki, T. Fukagawa, H. Katai, T. Ochiya, H. Sakamoto, H. Konno, T. Yoshida, H. Sasaki (2013) Intraperitoneal delivery of a small interfering RNA targeting NEDD1 prolongs the survival of scirrhous gastric cancer model mice. Cancer Sci 104: 214-222.

Grantab, R.H., I.F. Tannock (2012) Penetration of anticancer drugs through tumor tissue as a function of cellular packing density and interstitial fluid pressure and its modification by bortezomib. BMC Cancer 12: 214.

Hamada, H., M. Kobune, K. Nakamura, Y. Kawano, K. Kato, O. Honmou, K. Houkin, T. Matsunaga, Y. Niitsu (2005) Mesenchymal stem cells (MSC) as therapeutic cytoreagents for gene therapy. Cancer Sci 96: 149-156.

Hicklin, D.J., L.M. Ellis (2005) Role of the vascular endothelial growth factor pathway in tumor growth and angiogenesis. J Clin Oncol 23: 1011-1027.

-Hu, Y.L., Y.H. Fu, Y. Tabata, J.Q. Gao (2010) Mesenchymal stem cells: a promising targeteddelivery vehicle in cancer gene therapy. J Control Release 147: 154-162.

Hu, Y.L., B. Huang, T.Y. Zhang, P.H. Miao, G.P. Tang, Y. Tabata, J.Q. Gao (2012) Mesenchymal stem cells as a novel carrier for targeted delivery of gene in cancer therapy based on nonviral transfection. Mol Pharm 9: 26982709.

-Jain, R.K. (2013) Normalizing tumor microenvironment to treat cancer: bench to beside to biomarkers. J Clin Oncol 31: 2205-2218.

-Kanazawa, T., H. Nishino, M. Hasegawa, Y. Ohta, Y. Iino, K. Ichimura, Y. Noda (2007) Interleukin-6 directly influences proliferation and invasion potential of head and neck cancer cells. Eur Arch Otorhinolaryngol 264: 815-821.

Karnoub, A.E., A.B. Dash, A.P. Vo, A. Sullivan, M.W. Brooks, G.W. Bell, A.L. Richardson, K. Polyak, R. Tubo, R.A. Weinberg (2007) Mesenchymal stem cells within tumour stroma promote breast cancer metastasis. Nature 449: 557-563.

Khakoo, A.Y., S. Pati, S.A. Anderson, W. Reid, M.F. Elshal, I.I. Rovira, A.T. Nguyen, D. Malide, C.A. Combs, G. Hall, J. Zhang, M. Raffeld, T.B. Rogers, W. Stetler-Stevenson, J.A. Frank, M. Reitz, T. Finkel (2006) Human mesenchymal stem cells exert potent antitumorigenic effects in a model of Kaposi's sarcoma. J Exp Med 203: 1235-1247.

Kidd, S., L. Caldwell, M. Dietrich, I. Samudio, E.L. Spaeth, K. Watson, Y. Shi, J. Abbruzzese, M. Konopleva, M. Andreeff, F.C. Marini (2010) Mesenchymal stromal cells alone or expressing interferon-beta suppress pancreatic tumors in vivo, an effect countered by anti-inflammatory treatment. Cytotherapy 12: 615625.
Kucerova, L., V. Altanerova, M. Matuskova, S. Tyciakova, C. Altaner (2007) Adipose tissuederived human mesenchymal stem cells mediated prodrug cancer gene therapy. Cancer Res 67: 6304-6313.

Lee, R.H., B. Kim, I. Choi, H. Kim, H.S. Choi, K. Suh, Y. C. Bae, J.S. Jung (2004) Characterization and expression analysis of mesenchymal stem cells from human bone marrow and adipose tissue. Cell Physiol Biochem 14: 311324.

Li, L., Y. Guan, H. Liu, N. Hao, T. Liu, X. Meng, C. Fu, Y. Li, Q. Qu, Y. Zhang, S. Ji, L. Chen, D. Chen, F. Tang (2011) Silica nanorattle-doxorubicin-anchored mesenchymal stem cells for tumor-tropic therapy. ACS Nano 5: 74627470.

Li, X., L. Ding, Y. Xu, Y. Wang, Q. Ping (2009) Targeted delivery of doxorubicin using stealth liposomes modified with transferrin. Int J Pharm 373: 116-123.

Lin, W.R., M. Brittan, M.R. Alison (2008) The role of bone marrow-derived cells in fibrosis. Cells Tissues Organs 188: 178-188.

Lorusso, G., C. Rüegg (2008) The tumor microenvironment and its contribution to tumor evolution toward metastasis. Histochem Cell Biol 130: 1091-1103.

Moritake, S., S. Taira, Y. Ichiyanagi, N. Morone, S.Y. Song, T. Hatanaka, S. Yuasa, M. Setou (2007) Functionalized nano-magnetic particles for an in vivo delivery system. J Nanosci Nanotechnol 7: 937-944.

Multhoff, G., P. Vaupel (2012) Radiation-induced changes in microcirculation and interstitial fluid pressure affecting the delivery of macromolecules and nanotherapeutics to tumors. Front Oncol 2: 165

Pittenger, M.F., A.M. Mackay, S.C. Beck, R.K. Jaiswal, R. Douglas, J.D. Mosca, M.A. Moorman, D.W. Simonetti, S. Craig, D.R. Marshak (1999) Multilineage potential of adult human mesenchymal stem cells. Science 284: 143147.

Prestwich, R.J., D.Ç. Öksüz, K. Dyker, C. Coyle, M. Şen (2011) Feasibility and efficacy of induction docetaxel, cisplatin, and 5-fluorouracil chemotherapy combined with cisplatin concurrent chemoradiotherapy for nonmetastatic stage IV head-and-neck squamous cell carcinomas. Int J Radiat Oncol Biol Phys 81: 237-243.

Rhodes, L.V., S.E. Muir, S. Elliott, L.M. Guillot, J.W. Antoon, P. Penfornis, S.L. Tilghman, V.A. Salvo, J.P. Fonseca, M.R. Lacey, B.S. Beckman, J.A. McLachlan, B.G. Rowan, R. Pochampally, M.E. Burow (2010) Adult human mesenchymal stem cells enhance breast tumorigenesis and promote hormone independence. Breast Cancer Res Treat 121: 293300.

-Sadelain, M. (2004) Insertional oncogenesis in gene therapy: how much of a risk? Gene Ther 11: 569-573.
Scherzed, A., S. Hackenberg, K. Froelich, M. Kessler, C. Koehler, R. Hagen, A. Radeloff, G. Friehs, N. Kleinsasser (2011a) BMSC enhance the survival of paclitaxel treated squamous cell carcinoma cells in vitro. Cancer Biol Ther 11: 349-357.

Scherzed, A., S. Hackenberg, K. Froelich, A. Radeloff, A. Technau, M. Kessler, R. Hagen, K. Rak, C. Koehler, N. Kleinsasser (2011b) The effect of wound fluid on adipose-derived stem cells in vitro: a study in human cell materials. Tissue Eng Part C Methods 17: 809-817.

Schmidt, M., C. Polednik, P. Gruensfelder, J. Roller, R. Hagen (2009) The effects of PC-Spes on chemosensitive and chemoresistant head and neck cancer cells and primary mucosal keratinocytes. Oncol Rep 21: 1297-1305.

Spaeth, E.L., J.L. Dembinski, A.K. Sasser, K. Watson, A. Klopp, B. Hall, M. Andreeff, F. Marini (2009) Mesenchymal stem cell transition to tumor-associated fibroblasts contributes to fibrovascular network expansion and tumor progression. PLoS One 4: e4992.

Spaeth, E.L., S. Kidd, F.C. Marini (2012) Tracking inflammation-induced mobilization of mesenchymal stem cells. Methods Mol Biol 904: 173-190.

Sun, B., K.H. Roh, J.R. Park, S.R. Lee, S.B. Park, J.W. Jung, S.K. Kang, Y.S. Lee, K.S. Kang (2009) Therapeutic potential of mesenchymal stromal cells in a mouse breast cancer metastasis model. Cytotherapy 11: 289-298.

Tabe, Y., M. Konopleva, M.F. Munsell, F.C. Marini, C. Zompetta, T. McQueen, T. Tsao, S. Zhao, S. Pierce, J. Igari, E.H. Estey, M. Andreeff (2004) PML-RARalpha is associated with leptin-receptor induction: the role of mesenchymal stem cell-derived adipocytes in APL cell survival. Blood 103: 1815-1822.

Technau, A., K. Froelich, R. Hagen, N. Kleinsasser (2011). Adipose tissue-derived stem cells show both immunogenic and immunosuppressive properties after chondrogenic differentiation. Cytotherapy 13: 310-317.

Waugh, D.J., C. Wilson (2008) The interleukin-8 pathway in cancer. Clin Cancer Res 14: 67356741.

Yang, F., S.W. Cho, S.M. Son, S.R. Bogatyrev, D. Singh, J.J. Green, Y. Mei, S. Park, S.H. Bhang, B.S. Kim, R. Langer, D.G. Anderson (2010) Genetic engineering of human stem cells for enhanced angiogenesis using biodegradable polymeric nanoparticles. Proc Natl Acad Sci USA 107: 3317-3322.

Zenner, H.P, W. Lehner, I.F. Herrmann (1979) Establishment of carcinoma cell lines from larynx and submandibular gland. Arch Otorhinolaryngol 225: 269-277.

Zhu, Y, Z. Sun, Q. Han, L. Liao, J. Wang, C. Bian, J. Li, X. Yan, Y. Liu, C. Shao, R.C. Zhao (2009) Human mesenchymal stem cells inhibit cancer cell proliferation by secreting DKK-1. Leukemia 23: 925-933.
hMSC Promote Cancer Motility and Cytokine Secretion
Cells Tissues Organs 2013;198:327-337 DOI: $10.1159 / 000356731$ 